\title{
Taking Fetal Medicine to the Community
}

\author{
Sirisha R. Gundabattula $\cdot$ Evita Fernandez
}

Received: 31 October 2014 / Accepted: 17 November 2014/Published online: 26 November 2014

(C) Society of Fetal Medicine 2014

\begin{abstract}
Supplementing prenatal care with ultrasound technology has a significant impact on improving maternal and perinatal health by identifying at-risk pregnancies and directing deliveries to hospital settings. Ectopic pregnancies, placenta praevia, multiple pregnancy, fetal malposition, and abnormal fetal growth are known to increase morbidity and mortality, and can be diagnosed using ultrasound. We are now able to predict complications in pregnancy as early as the 12th week. The routine use of fetal ultrasound and innovations in fetal therapy raise several moral dilemmas including the unequal distribution of supporting health care and nonavailability of these services to a large proportion of the population residing in developing countries. Several strategies are available to improve delivery of these services: central government provision, contracting out to the private sector and NGOs, decentralization to local governments and community participation. Focused training of fetal medicine specialists, midwives, nurses, and technicians and provision of supporting infrastructure can deliver results and possibly eliminate the disparities in health care.
\end{abstract}

Based on the oration given at the 2nd International Congress of the Society of Fetal Medicine, Hyderabad, 30th August-1st September, 2013.

\section{S. R. Gundabattula ( $\square)$}

Department of Gynecology, Fernandez Hospital Pvt. Ltd., 4-1-1230, Bogulkunta, Hyderabad 500001, Andhra Pradesh, India

e-mail: drsirisha.g@fernandezhospital.com

E. Fernandez

Department of Obstetrics, Fernandez Hospital Pvt. Ltd., 4-1-1230, Bogulkunta, Hyderabad 500001, Andhra Pradesh, India
Keywords Community - Fetal medicine - Mortality rate . Obstetric ultrasound $\cdot$ Prenatal diagnosis $\cdot$ Training and research

\section{Introduction}

Fetal medicine deals with the assessment of fetal growth and wellbeing, the maintenance of fetal health and the diagnosis of fetal illnesses and abnormalities. The health of the mother and the fetus are inseparably linked, and fetal medicine is pivotal to prevent maternal and fetal mortality, morbidity and disability.

\section{Scope of Fetal Medicine}

Obstetric ultrasonography has revolutionized the management of pregnancy by providing a window into the womb and allowing identification of previously unknown problems in the fetus.

- Prenatal screening: Serum beta human chorionic gonadotropin and pregnancy-associated plasma protein-A in conjunction with ultrasonography for nuchal translucency; targeted imaging for fetal anomalies; quadruple screen.

- Prenatal diagnosis: Chorionic villus sampling, amniocentesis, cordocentesis, fetal biopsy, nonstress test, biophysical profile, Doppler sonography; MRI may be a useful adjunct in certain situations.

- Fetal therapy: Medical treatment (hypothyroidism, congenital arrhythmias), surgical options such as ultrasound-guided vesicoamniotic shunt placement, fetoscopic procedures in twin-to-twin transfusion and open 
fetal surgery (congenital diaphragmatic hernia, sacrococcygeal teratoma). Future research will inevitably expand the number of conditions that can be identified early and treated in pregnancy.

\section{Impact of Fetal Medicine on Maternal and Neonatal Outcomes}

Cause-specific mortality and age-standardized mortality rates indicate whether progress is being made in reducing the number of premature/avoidable deaths. In 2010, maternal causes accounted for $10.7 \%$ of deaths in women aged 15-34 years. Haemorrhage and hypertension are among the top three causes of maternal death in South Asia and sub-Saharan Africa where majority of maternal deaths occur $[1,2]$. Neonatal deaths account for $40.3 \%$ of the under-5 mortality. Preterm birth complications, intrapartum-related complications and sepsis are the leading causes of neonatal death [3]. Two examples to illustrate the role of fetal medicine are: early identification of adherent placenta, a cause of significant haemorrhage, by imaging facilitates effective planned management (minimizes maternal morbidity) and cervical length screening and subsequent treatment with progesterone or cerclage in appropriately selected women is an effective preventive strategy for preterm birth (reduces neonatal morbidity) [4].

In the current conventional system of antenatal care, the high concentration of visits in the third trimester implies that most complications occur at this stage of pregnancy and most adverse outcomes are not identifiable during the first or even second trimester. Nicolaides proposed that this pyramid should be inverted with the main emphasis placed in the first trimester [5]. The patient-specific risk for many complications such as fetal abnormalities, miscarriage, stillbirth, pre-eclampsia, preterm delivery, gestational diabetes, fetal growth restriction and macrosomia can be predicted at the 11-13 weeks' scan by combining data from maternal characteristics and history with findings of biophysical and biochemical tests. Early estimation of risks would improve pregnancy outcome by shifting prenatal care from a series of routine visits to a more individualized patient- and disease-specific approach.

\section{What are the Challenges?}

The greatest challenge is the provision of equitable, evidence-based, quality health care that is accessible, affordable and available to all segments of the population. Services work when they include all people, but too often, they fail the poor-in access, in quantity, in quality. The tragic misuse of technology is exemplified by instances of pregnancy terminations for nonlethal minor malformations and unconfirmed screen-positives. One cannot be oblivious to the female feticide rampant in some states of India. Despite stringent laws governing prenatal diagnosis and sex determination, the sex ratio at birth has dropped to less than 800 in some parts of the country [6].

Ethically, the fetus as a patient is thought of in different, often competing ways and lack of legal clarity further confounds decision making, such as defining the limits of viability and maternal beneficence and autonomy versus fetal beneficence and autonomy. Recent innovations in fetal medicine, complex risk and diagnostic information and uncertain prognostications are leading to unprecedented ethical, legal, and social issues [7].

\section{Indian Scenario}

Is India shining? 'India Shining' was a marketing slogan referring to the overall feeling of economic optimism in India in 2004. But India seems to be shining only for a small section of society, for the middle class strata and above; for the vast majority in the other India, even basic human needs are not being met. India, with a population exceeding 1 billion, is one of the worst performing countries in the world (Table 1).

\section{Reaching the Community}

Health care is a human right and success must not be measured by its technical virtues or its scientific precision but rather by its capacities to meet needs and improve the quality of life. Implementation of an effective care strategy is an overwhelming priority [10]. The following initiatives may help bridge the gap in health care services:

Table 1 Health statistics of India, 2012 [8, 9]

\begin{tabular}{ll}
\hline Antenatal care-at least 1 visit & $74.2 \%$ \\
Antenatal care-at least 4 visits & $37.0 \%$ \\
Skilled attendant at birth & $52.3 \%$ \\
Maternal mortality rate & 210 per 1,00,000 \\
& live births (190 in 2013) \\
Exclusive breast feeding & $46.4 \%$ \\
Infant mortality rate & 44 per 1,000 live births \\
Under-5 mortality rate & 56 per 1,000 live births \\
Contraceptive prevalence & $54.8 \%$ \\
Urbanized population & $31.6 \%$ \\
GDP allocated to health & $1.1 \%$ \\
GDP allocated to education & $3.3 \%$ \\
\hline
\end{tabular}


- Increased resource allocations for maternal, newborn and child health

- Health-center intrapartum care strategy (alternatively, delivery at primary-level institutions backed up by access to referral-level facilities)

- Policies targeted at antenatal care, postpartum care and family planning

- Decentralization and community participation [community health workers called Accredited Social Health Activists (ASHAs) employed by National Rural Health Mission]

- Collaboration between public and private sectors

- Active participation of nongovernmental and voluntary organizations: Fetal Care Research Foundation (free prenatal services for the underprivileged), Health Management and Research Institute (Health Information Helpline, Mobile Health Services and Telemedicine Services), Down Syndrome Federation of India (counseling, physiotherapy, speech therapy, spreading awareness)

\section{Fetal Medicine Reaching the Community}

- Documentation and maintenance of registries (Birth Defects Registry of India with a mission to ascertain nationwide baseline prevalence of birth defects and reduce the incidence)

- Training and research in fetal medicine (on the lines of educational programme and grants provided by the Fetal Medicine Foundation that can be undertaken by the Society of Fetal Medicine)

- Focused training of midwives, nurses and technicians (hands-on training in ultrasound supported by essential theoretical knowledge which should be the one provided by the International Society of Ultrasound in Obstetrics and Gynecology Outreach program)
Fetal medicine is an integral component of maternity services. India needs to train more people to use this technology to its optimum best.

Conflict of interest None.

Funding None.

\section{References}

1. Lozano R, Naghavi M, Foreman K, et al. Global and regional mortality from 235 causes of death for 20 age groups in 1990 and 2010: a systematic analysis for the global burden of disease study 2010. Lancet. 2012;380:2095-128.

2. Countdown to 2015 decade report (2000-2010): taking stock of maternal, newborn and child survival. http://whqlibdoc.who.int/ publications/2010/9789241599573_eng.pdf.

3. Liu L, Johnson HL, Cousens S, Perin J, Scott S, Lawn JE, et al. Child Health Epidemiology Reference Group of WHO and UNICEF. Global, regional, and national causes of child mortality: an updated systematic analysis for 2010 with time trends since 2000. Lancet. 2012;379(9832):2151-61.

4. Incidentally detected short cervical length. Committee Opinion No. 522. American College of Obstetricians and Gynecologists. Obstet Gynecol. 2012;119:879-82.

5. Nicolaides KH. Turning the pyramid of prenatal care. Fetal Diagn Ther. 2011;29:183-96.

6. SRS Report 2012. Registrar General and Census Commissioner, Ministry of Home Affairs, Government of India. 2014. http:// www.censusindia.gov.in/vital_statistics/SRS_Report_2012/10_ Chap_3_2012.pdf. Accessed 19 April 2014.

7. Williams C. Dilemmas in fetal medicine: premature application of technology or responding to women's choice? Sociol Health Illn. 2006;28(1):1-20.

8. UNICEF India statistics.2013. http://www.unicef.org/infoby country/india_statistics.html. Accessed 27 Dec 2013.

9. WHO Global Health Observatory. http://www.who.int/gho/coun tries/ind/country_profiles/en/.

10. Campbell OMR, Graham WJ. Strategies for reducing maternal mortality: getting on with what works. Lancet. 2006;368: 1284-99. 